Multilayer deposition and EUV reflectance characterization of $131 \AA$ flight mirrors for AIA at LLNL

R. Soufli, J. C. Robinson, E. Spiller, S. L. Baker, F. J. Dollar, E. M. Gullikson

May 24, 2006 
This document was prepared as an account of work sponsored by an agency of the United States Government. Neither the United States Government nor the University of California nor any of their employees, makes any warranty, express or implied, or assumes any legal liability or responsibility for the accuracy, completeness, or usefulness of any information, apparatus, product, or process disclosed, or represents that its use would not infringe privately owned rights. Reference herein to any specific commercial product, process, or service by trade name, trademark, manufacturer, or otherwise, does not necessarily constitute or imply its endorsement, recommendation, or favoring by the United States Government or the University of California. The views and opinions of authors expressed herein do not necessarily state or reflect those of the United States Government or the University of California, and shall not be used for advertising or product endorsement purposes.

This work was performed under the auspices of the U.S. Department of Energy by University of California, Lawrence Livermore National Laboratory under Contract W-7405-Eng-48. 


\title{
Multilayer deposition and EUV reflectance characterization of $131 \AA$ flight mirrors for AIA at LLNL
}

\author{
Regina Soufli ${ }^{1}$, Jeff C. Robinson ${ }^{1}$, Eberhard Spiller ${ }^{1}$, Sherry L. Baker ${ }^{1}$, Franklin J. Dollar ${ }^{2}$, \\ Eric M. Gullikson ${ }^{2}$ \\ ${ }^{1}$ Lawrence Livermore National Laboratory, Livermore, California \\ ${ }^{2}$ Lawrence Berkeley National Laboratory, Berkeley, California
}

\begin{abstract}
SUMMARY
Mo/Si multilayer coatings reflecting at $131 \AA$ were deposited successfully on the AIA primary and secondary flight mirrors and on two coating witness Si wafers, on November 16, 2005, at LLNL. All coatings were characterized by means of EUV reflectance measurements at beamline 6.3.2 of the Advanced Light Source (ALS) synchrotron at LBNL, and were found to be well within specifications.
\end{abstract}

\section{EXPERIMENTAL SETUP}

Prior to depositing any multilayer coatings, both primary (Sagem 04R0416) and secondary (Sagem 04R0420) flight substrates were cleaned at LLNL using a custom-designed process. The AIA flight deposition run at $131 \AA$ was performed with a large-optics DC-magnetron sputtering system, which is located in a cleanroom facility at LLNL and is shown in Figs. 1, 2, 3. The tool has a "sputter down" geometry shown in Fig. 1 (left), with five sputtering targets available (Fig.2, right). The deposition tool allows the coating of large optics (up to four large substrates can be accommodated in the chamber in a single deposition) and the off-center mounting and spinning of optics with the possibility of graded coatings ${ }^{1}$. For the $\mathrm{Mo} / \mathrm{Si}$ flight deposition run discussed in this report, a pair of Mo and Si sources were used and the substrate positions were labeled A1 through A4 with the flight substrates in A2 (secondary) and A3 (primary) and coating witnesses in A1 and A4 (Fig. 3). On each flight mirror, a D-shaped mask was used during deposition to protect half of the mirror area, previously coated with $\mathrm{Mg} / \mathrm{SiC}$ at Columbia University. Furthermore, a strip of Kapton tape was used to protect the $\mathrm{Mg} / \mathrm{SiC}$ coating in the region across the centerline. Silicon wafers of $100 \mathrm{~mm}$ diameter, 510-530 $\mu \mathrm{m}$ thickness and (100) orientation were used as coating witness substrates in positions A1 and A4. The Mo source was operated at a power of $800 \mathrm{~W}$ and the Si source at 2000 $\mathrm{W}$. Base pressure was maintained at $2 \times 10^{-8}$ Torr and the Ar sputtering gas pressure was at $1 \mathrm{mTorr}$. During the multilayer deposition run, the platter is rotating under the sources at speeds in the $1 \mathrm{rpm}$ range, while the individual substrates are simultaneously spinning around their centers, in order to average out spatial variations of the sputtering sources and achieve azimuthal uniformity. Spinning velocities are set to $400 \mathrm{rpm}(6.7 \mathrm{~Hz})$ for the multilayer coatings discussed in this work. To achieve the desired multilayer thickness profile in the radial (lateral) direction for a given flat or curved substrate, the platter speed is modulated as each substrate passes under the Si and Mo targets. A computer model is implemented at LLNL that simulates the deposition process and predicts the velocity modulation algorithm needed to achieve the desired thickness profile on a given substrate 
surface. This process is rapidly converging and produced the goal profiles on both AIA mirrors after only a few coating iterations, during the development phase of this project ${ }^{2}$. Absolute platter velocities are adjusted in order to achieve the desired Mo/Si bilayer thickness (which determines the peak wavelength) for each substrate. The two AIA flight mirrors are shown in Fig. 4 after Mo/Si multilayer coating and EUV reflectance measurements were completed. The ratio of Mo thickness in the $\mathrm{Mo} / \mathrm{Si}$ bilayer was 0.36 , a total of $\mathrm{N}=50$ bilayers were applied and finished with a $\mathrm{Si}$ capping layer, as was determined earlier in the development phase of this project ${ }^{3,4}$.

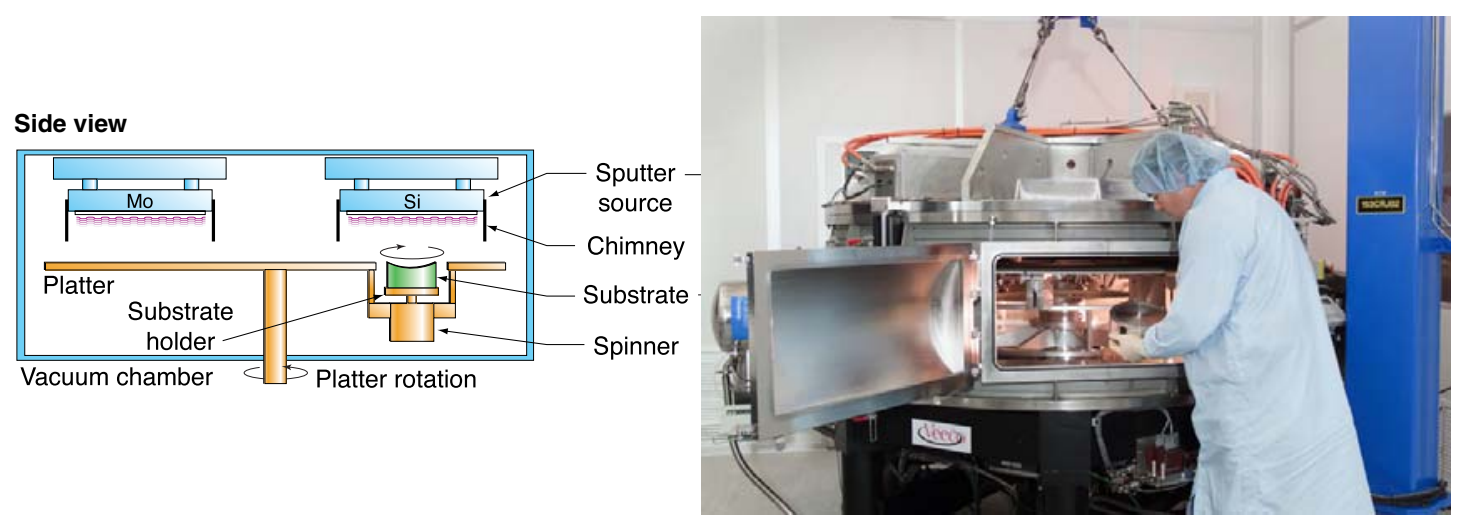

Figure 1: Side view of the LLNL large-optics DC-magnetron sputtering system. The photograph on the right displays an optic being introduced into the chamber through a side door.
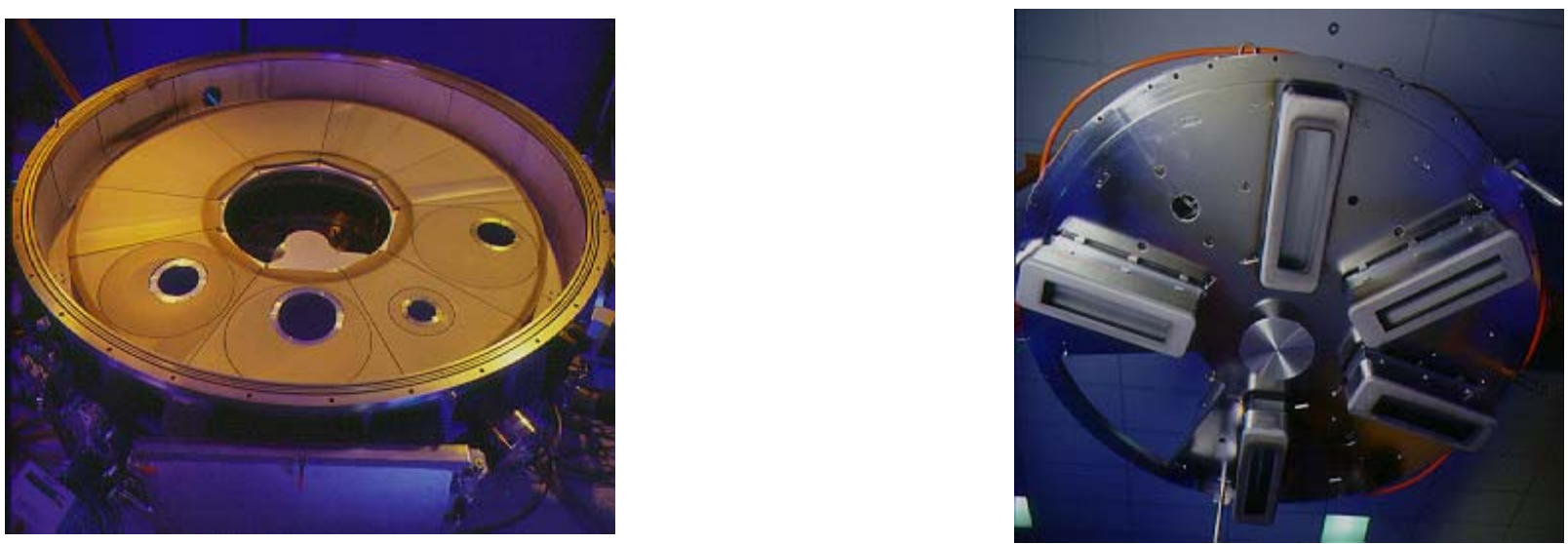

Figure 2: Left: View of substrate platter, with four silicon wafers of various sizes mounted on on-axis and off-axis positions. Right: Underneath view of chamber lid with five sputtering targets. 


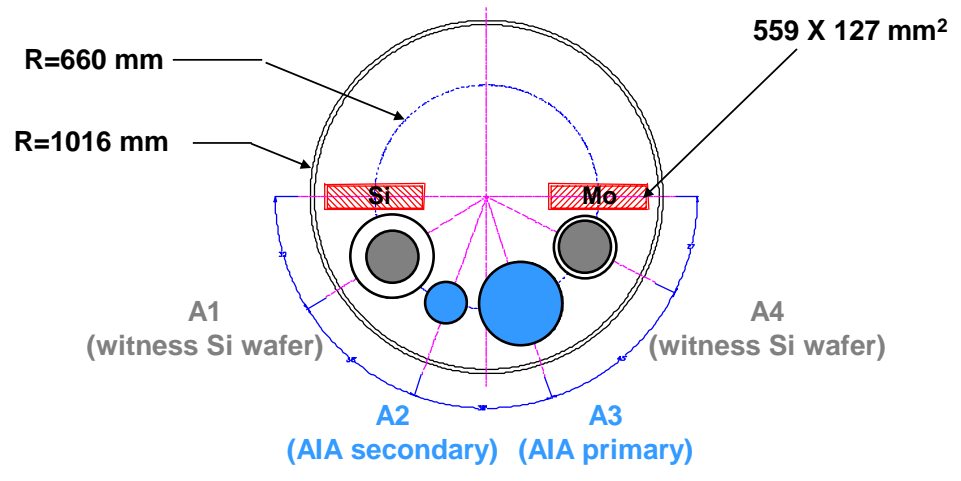

Figure 3: Top-view diagram of the multilayer deposition platter with AIA flight substrates and witnesses

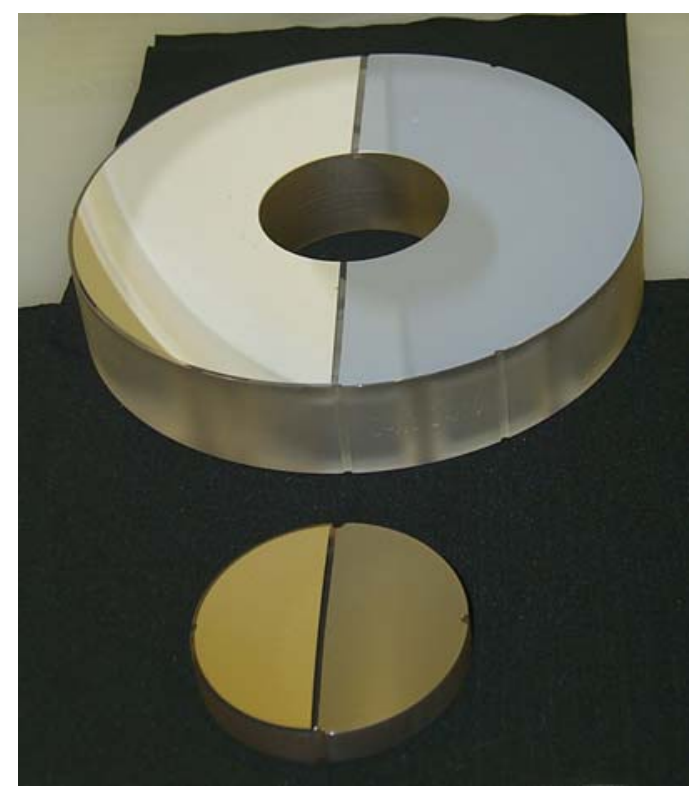

Figure 4: Multilayer-coated AIA flight mirror pair at $335 \AA$ (left side, $\mathrm{Mg} / \mathrm{SiC}$, performed at Columbia University) and $131 \AA$ (right side, Mo/Si, performed at LLNL). The mirrors are shown on the cleanroom bench inside the LLNL multilayer lab, after EUV reflectance measurements were completed and prior to installing and packing in the SAO shipping containers. 
All EUV reflectance measurements presented in this report were measured at beamline 6.3.2. of the ALS synchrotron at LBNL. The characteristics of the beamline and its reflectometer have been described in detail earlier ${ }^{5,6}$. Curved optics of up to $200 \mathrm{~mm}$ in diameter can be mapped in this facility. The reflectometer sample stage, shown in Fig. 5, allows motion of the optic in 3 dimensions, tilt in 2 dimensions and azimuthal rotation of the sample holder. The detector arm has photodiode, CCD camera, and wire detector mounted and can be rotated $360^{\circ}$ around the axis of the reflectometer chamber. Once an optic is aligned with the CCD camera, custom-designed software allows the operator to pre-calculate for each surface point a table of all coordinates of the sample stage, and program measurements (EUV wavelength scans in the case of the AIA optics) on multiple locations on the mirror surface without any manual input needed in-between scans. Mirrors are measured in their coating fixtures.

Specifically for the measurements in the $131 \AA$ region discussed in this report, a 200 lines $/ \mathrm{mm}$ grating was used in the monochromator, and the monochromator exit slit was set to a width of $50 \mu \mathrm{m}$ thus achieving spectral resolving power $\lambda / \Delta \lambda=1300$. Wavelength $\lambda$ was calibrated based on the $\mathrm{Si}$ $\mathrm{L}_{2,3}$ absorption edge with a relative accuracy of $0.011 \% \mathrm{rms}$, and could be determined with $0.007 \%$ repeatability. During the measurements, second harmonic and stray light suppression was achieved with a Be filter. For higher-order harmonic suppression, an "order suppressor" consisting of three $\mathrm{C}$ mirrors at a grazing incidence angle of $10^{\circ}$ was used in addition to the Be filter. In this manner, a spectral purity of $99.9 \%$ or better was achieved throughout the measurements. The ALS storage ring current was used to normalize the signal against the storage ring current decay. The base pressure in the measurement chamber was at $10^{-6}$ Torr. The signal was collected on a Si photodiode detector with a $10 \times 10-\mathrm{mm}^{2}$ active area and acceptance angle of $2.4^{\circ}$. All wavelength and reflectance results were obtained within " $2 \sigma$ " error bars of $0.05 \%$ and $0.4 \%$ relative (the latter limited by photodiode uniformity), respectively. The measurement angle for all flight mirrors and witnesses was set at grazing angle $\theta_{\text {meas }}=87^{\circ}$ and was later translated to the actual AIA angles of incidence as is discussed in the next section. Geometrical constraints inside the reflectometer prevent measurements at the actual AIA angles of incidence.

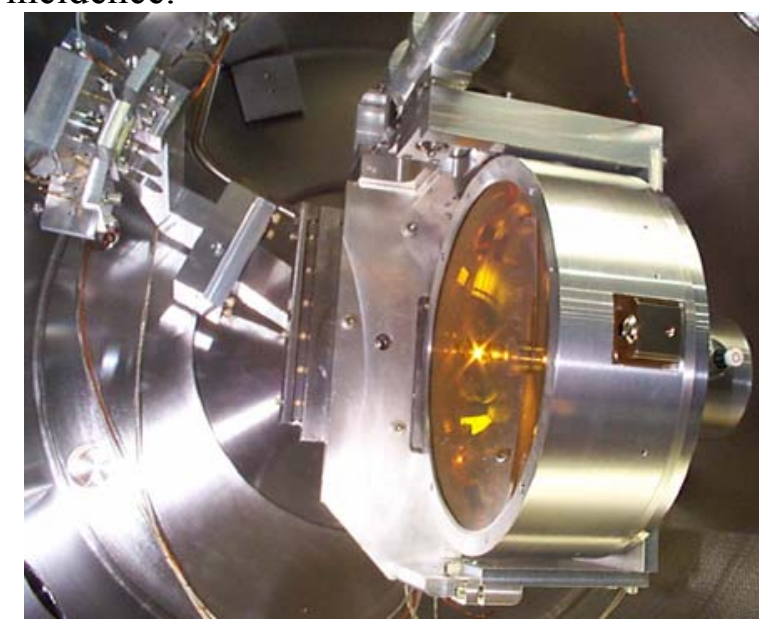

Figure 5: Interior of reflectometer chamber at ALS beamline 6.3.2. with a mounted optic. The detector arm is also shown (top left). 


\section{RESULTS AND DISCUSSION}

The prescription for the primary and secondary AIA mirror surfaces is given by

$$
z(r)=\frac{1}{R} \cdot \frac{r^{2}}{\left[1+\sqrt{1-(1+K) \cdot(r / R)^{2}}\right]},
$$

where $\mathrm{z}$ is the surface height, $\mathrm{r}$ is the radial position defined from the optical axis of each mirror, $\mathrm{R}$ is the radius of curvature and $\mathrm{K}$ is the conic constant. Table 1 summarizes the values of $\mathrm{R}$ and $\mathrm{K}$, as well as the mirror and clear aperture radii and incidence angles for the AIA mirrors. As is noted in Table 1, the angles of incidence for both mirrors are very close to the normal direction and vary only slightly across the clear aperture. Therefore, uniform multilayer coatings were prescribed for both primary and secondary mirrors of the AIA instrument. The AIA primary and secondary optics were measured across the radial direction (r) in the center of the coated area $\left(\varphi=0^{\circ}\right)$, as shown in Figure 6. 12 points (primary) and 9 points (secondary) were measured, including the edge points of the clear aperture of each mirror. Figure 7 shows the measured results from the two witness Si wafer substrates mounted in substrate positions A1, A4. After the measurements were completed, two pieces were cut within a $50 \times 50 \mathrm{~mm}^{2}$ center area of the A1 sample and attached to the SAO primary and secondary shipping containers as coating witness pieces, using sample holder nos. $\mathrm{C} 11$ and $\mathrm{C} 12$, respectively. The multilayer-coated Si wafer from substrate position A4 has been maintained intact. Table 2 summarizes the wavelength results from flight mirrors and witness samples. For wavelength calibration purposes, a point near the center of the clear aperture of each mirror $(\mathrm{r}=60 \mathrm{~mm}$ for the primary and $\mathrm{r}=25 \mathrm{~mm}$ for the secondary) was selected to meet the goal peak wavelength of $131.0 \AA$, where the thickness profile is relatively "flat" and the angle of incidence in the AIA camera is $\theta_{\mathrm{i}}=$ $88.8^{\circ}$ for the primary and $\theta_{\mathrm{i}}=91.2^{\circ}$ for the secondary, i.e: $1.2^{\circ}$ from the normal direction for both mirrors. The goal peak wavelength was also set to $131.0 \AA$ at $\theta_{\mathrm{i}}=88.8^{\circ}$ for the two coating witnesses A1, A4. The measured results in Table 2 demonstrate that both flight mirrors and coating witnesses meet the goal wavelength within $0.1 \AA$. The Bragg diffraction relation for multilayers was used to translate the measured wavelengths at $\theta_{\text {meas }}=87^{\circ}$ to the actual AIA angle of incidence $\theta_{i}$, using refractive index values for Mo and $\mathrm{Si}$ from the CXRO database, where the values for Mo and $\mathrm{Si}$ in the $131 \AA$ region have been updated with experimental results reported in the literature ${ }^{7,8,9}$. Measured reflectivity curves vs. wavelength for flight mirrors and coating witnesses are shown in Figure 7. Both coating witnesses (with substrate roughness $\leq 1 \AA$ in the high-spatial frequency range) achieved peak reflectance of $68.3 \%$. The reflectivity of the flight mirrors is consistent with the flight substrate roughness, which has been measured earlier at LLNL by means of Atomic Force Microscopy $(\mathrm{AFM})^{10,11}$. Table 3 summarizes the high-spatial frequency roughness and reflectivity results for the flight mirrors, including a prediction of the reflectance loss due to substrate roughness.

The predicted reflectance loss was calculated with the distorted wave Born approximation ${ }^{12}$ using the AFM-measured power spectral density of the substrate. The effect of the DC-magnetron sputtered Mo/Si multilayer was included using a linear growth model ${ }^{13}$. 


\begin{tabular}{|c|c|c|}
\hline & Primary (concave) & Secondary (convex) \\
\hline $\mathbf{R}(\mathbf{m m})$ & $2755.01 \pm 1$ & $1208.57 \pm 0.4$ \\
\hline $\mathbf{K}$ & -1.0916 & -5.0766 \\
\hline Mirror outer radius (mm) & 100.0 & 39.9 \\
\hline $\begin{array}{c}\text { Clear aperture } \\
\text { outer radius (mm) }\end{array}$ & 94.0 & 34.0 \\
\hline $\begin{array}{c}\text { Clear aperture } \\
\text { inner radius (mm) }\end{array}$ & 45.1 & 9.0 \\
\hline "Dead strip" width (mm) & 3.05 & 1.0 \\
\hline $\begin{array}{c}\text { Range of incidence angles } \\
\text { within clear aperture }\end{array}$ & $89.1^{\circ}-88.0^{\circ}$ & $90.4^{\circ}-91.8^{\circ}$ \\
\hline
\end{tabular}

Table 1: AIA mirror parameters are shown, including the dead strip width from the center line of each mirror, for the 131/335 A telescope. Angles of incidence are defined from the grazing direction. Optical design by W. A. Podgorski (Smithsonian Astrophysical Observatory).
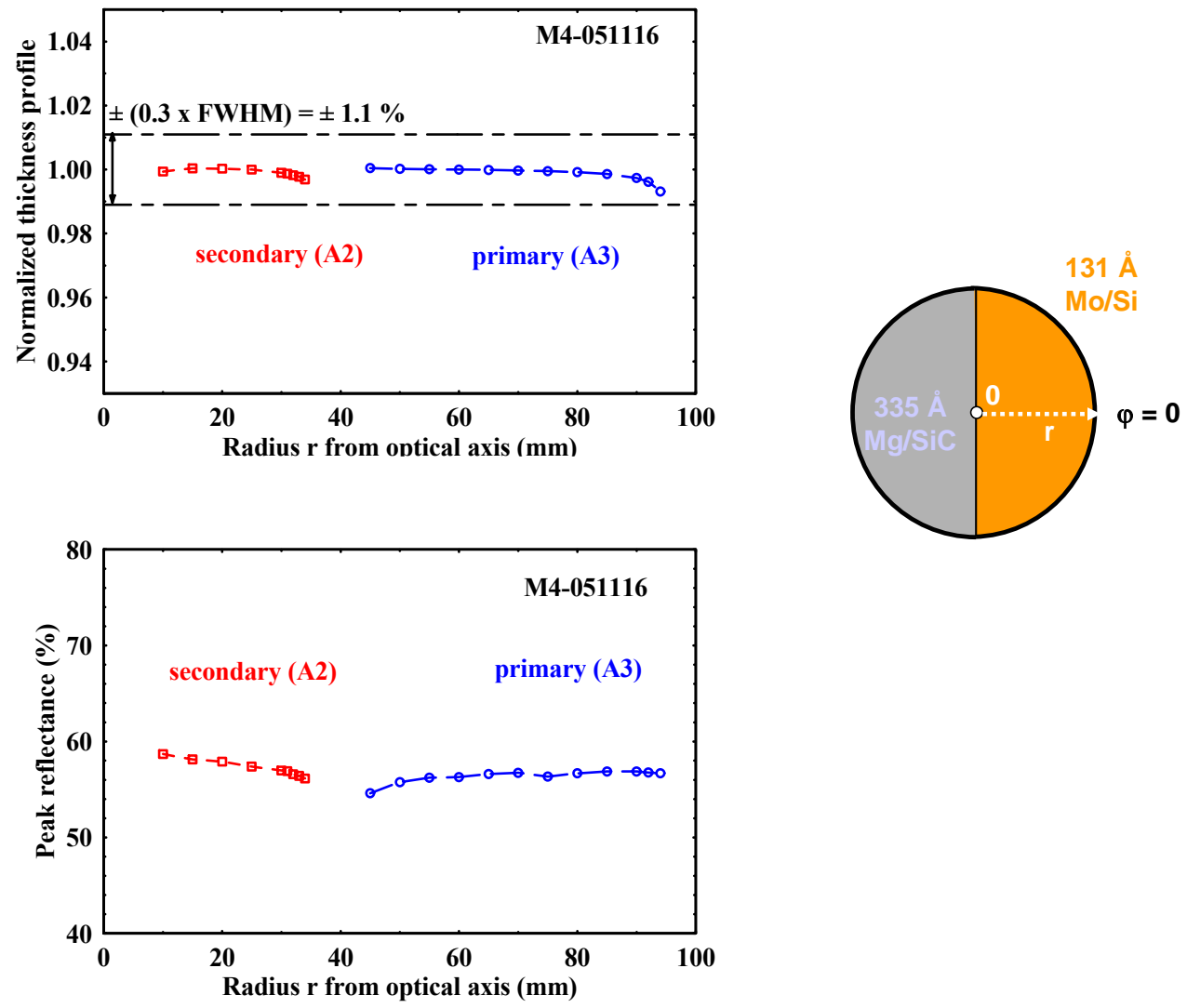

Figure 6: Normalized thickness profile (top) and peak EUV reflectance (bottom) results are measured in the radial direction, at $\varphi=0^{\circ}$. The multilayer thickness uniformity meets AIA specification across the entire clear aperture. 


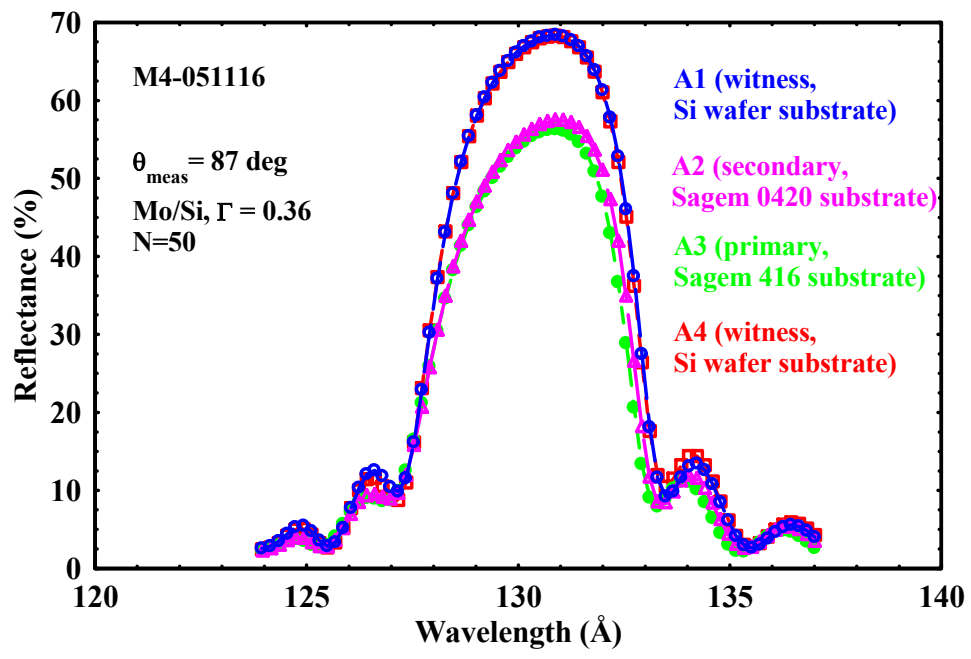

Figure 7: EUV reflectance curves are shown for AIA flight mirrors and witnesses, measured at the center of each optic.

\begin{tabular}{|l|c|c|c|c|}
\hline $\begin{array}{l}\text { Substrate } \\
\text { Position }\end{array}$ & $\begin{array}{c}\lambda_{\text {peak }} \text { at } \theta_{\text {meas }}=\mathbf{8 7}^{\mathbf{0}} \\
(\mathbf{\AA})\end{array}$ & $\begin{array}{c}\lambda_{\text {peak }} \text { at } \theta_{\mathbf{i}} \\
(\mathbf{\AA})\end{array}$ & $\begin{array}{c}\text { goal } \lambda_{\text {peak }} \text { at } \theta_{\mathbf{i}} \\
(\AA)\end{array}$ & $\begin{array}{c}\text { FWHM } \\
(\AA)\end{array}$ \\
\hline A1 (Si wafer) & 130.80 & 130.96 & 131.00 & 4.78 \\
\hline A2 (secondary) & 130.94 & 131.10 & 131.00 & 4.66 \\
\hline A3 (primary) & 130.84 & 131.00 & 131.00 & 4.57 \\
\hline A4 (Si wafer) & 130.81 & 130.97 & 131.00 & 4.77 \\
\hline
\end{tabular}

Table 2: Measured peak wavelength results are shown for AIA flight mirrors and witnesses, compared to the goal wavelength. The wavelengths corresponding to the actual AIA angles of incidence $\theta_{\mathrm{i}}$ are shown in blue. The measured FWHM of each optic is also shown in blue.

\begin{tabular}{|l|l|l|}
\hline \multicolumn{1}{|c|}{ Mirror } & \multicolumn{1}{c|}{$\begin{array}{c}\text { Primary } \\
\text { (Sagem 04R0416) }\end{array}$} & $\begin{array}{c}\text { Secondary } \\
\text { (Sagem 04R0420) }\end{array}$ \\
\hline Substrate roughness $(\mathbf{\AA}$ rms) & 5.0 & 5.2 \\
\hline $\mathbf{R}_{\text {peak }}(\%)$ & 56.2 & 58.8 \\
\hline $\boldsymbol{\Delta R}(\%$, absolute) & 8.5 & 8.4 \\
\hline $\mathbf{R}_{\text {peak }}+\Delta \mathbf{R}$ & 64.7 & 67.2 \\
\hline
\end{tabular}

Table 3: High-spatial frequency roughness of the substrate, peak EUV reflectance $\left(\mathrm{R}_{\text {peak }}\right)$, and predicted reflectance loss $\Delta \mathrm{R}$ are shown for each AIA flight mirror. AFM measurements on five (primary) and four (secondary) locations on the surface were averaged to produce the substrate roughness values. Reflectance measurements on 66 locations on each mirror surface were averaged to produce the peak reflectance values. For the AIA primary mirror, $\mathrm{R}_{\text {peak }}+\Delta \mathrm{R}$ is lower by $3.7 \%$ compared to $68.3 \%$ reflectance measured on smooth $\mathrm{Si}$ wafer substrates. This slight difference could be attributed to different locations and number of points between the AFM and EUV reflectance measurements on the primary mirror, and uncertainty in the model used to predict $\Delta \mathrm{R}$. For the AIA secondary mirror, $\mathrm{R}_{\text {peak }}+\Delta \mathrm{R}$ is consistent with the reflectance measured on smooth Si wafer substrates. 
In addition to the radial measurements at $\varphi^{\circ} 0^{\circ}$ shown in Fig. 6, the EUV reflectance of the flight mirrors was measured with 2-dimensional scans on 78 locations across the surface of each mirror. On the primary mirror, 6 radii $\mathrm{r}=45,60,75,90,92,94 \mathrm{~mm}$ were measured at 13 azimuth angles $\varphi=$ $\pm 90^{\circ}, \pm 85^{\circ}, \pm 80^{\circ}, \pm 75^{\circ}, \pm 60^{\circ}, \pm 30^{\circ}, 0^{\circ}$. The results are shown in Fig. 8. It should be noted that $\mathrm{r}=$ $45,94 \mathrm{~mm}$ are at the edge of the clear aperture. Furthermore, due to the specified "dead strip" width of $3.05 \mathrm{~mm}, \varphi= \pm 90^{\circ}$ is outside the clear aperture for all radii. The AIA specification is that peak wavelength should be within $\pm(0.3 \times \mathrm{FWHM})= \pm 1.4 \AA$, or wavelength uniformity should be within $\pm 1.1 \%$ peak-to-valley $(\mathrm{P}-\mathrm{V})$, in $80 \%$ of the clear aperture. The results plotted in Fig. 8 demonstrate that the primary mirror wavelength uniformity is within $\pm(0.3 \times \mathrm{FWHM})$ in $100 \%$ of the clear aperture. Furthermore, from the results in Fig. 8 it is calculated that in $80 \%$ of the clear aperture the wavelength uniformity is within $\pm 0.2 \% \mathrm{P}-\mathrm{V}$.
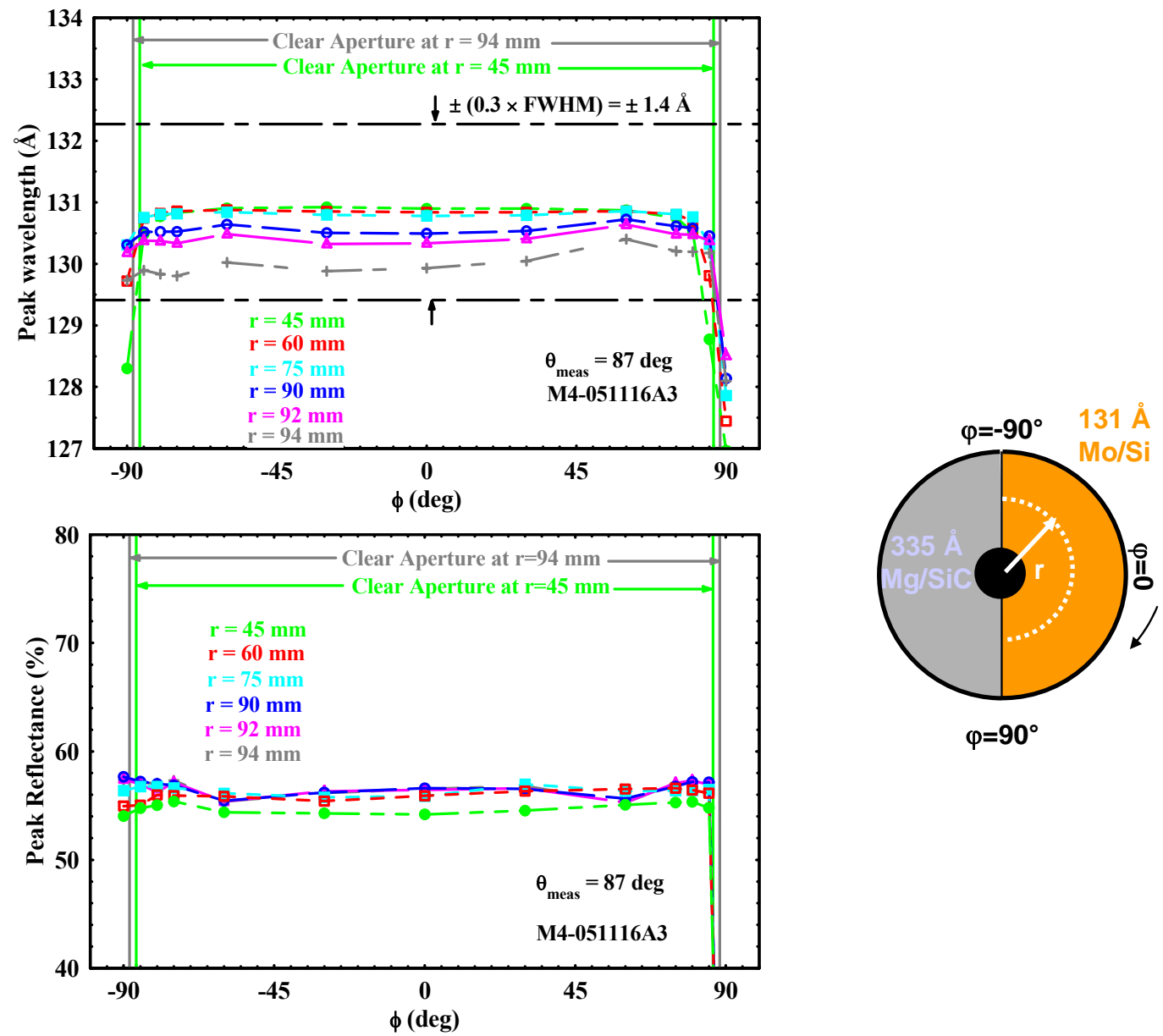

Figure 8: Peak wavelength (top) and reflectance (bottom) results for the primary mirror, measured at 78 locations across the surface. 
On the secondary mirror, 6 radii $\mathrm{r}=9,12,20,30,32,34 \mathrm{~mm}$ were measured at 13 azimuth angles $\varphi$ $= \pm 90^{\circ}, \pm 85^{\circ}, \pm 80^{\circ}, \pm 75^{\circ}, \pm 60^{\circ}, \pm 30^{\circ}, 0^{\circ}$. The results are shown in Fig. 9. It should be noted that $\mathrm{r}$ $=9,34 \mathrm{~mm}$ are at the edge of the clear aperture and, due to the specified "dead strip" width of $1 \mathrm{~mm}$, $\varphi= \pm 90^{\circ}$ is outside the clear aperture for all radii and $\varphi= \pm 85^{\circ}$ is outside the clear aperture for $r=9$ $\mathrm{mm}$. The AIA specification is that peak wavelength should be within $\pm(0.3 \times \mathrm{FWHM})= \pm 1.4 \AA$ (or wavelength uniformity should be within $\pm 1.1 \% \mathrm{P}-\mathrm{V}$ ) in $80 \%$ of the clear aperture. The results plotted in Fig. 9 demonstrate that the secondary mirror wavelength uniformity is within $\pm 0.4 \% \mathrm{P}-\mathrm{V}$ in $80 \%$ of the clear aperture.
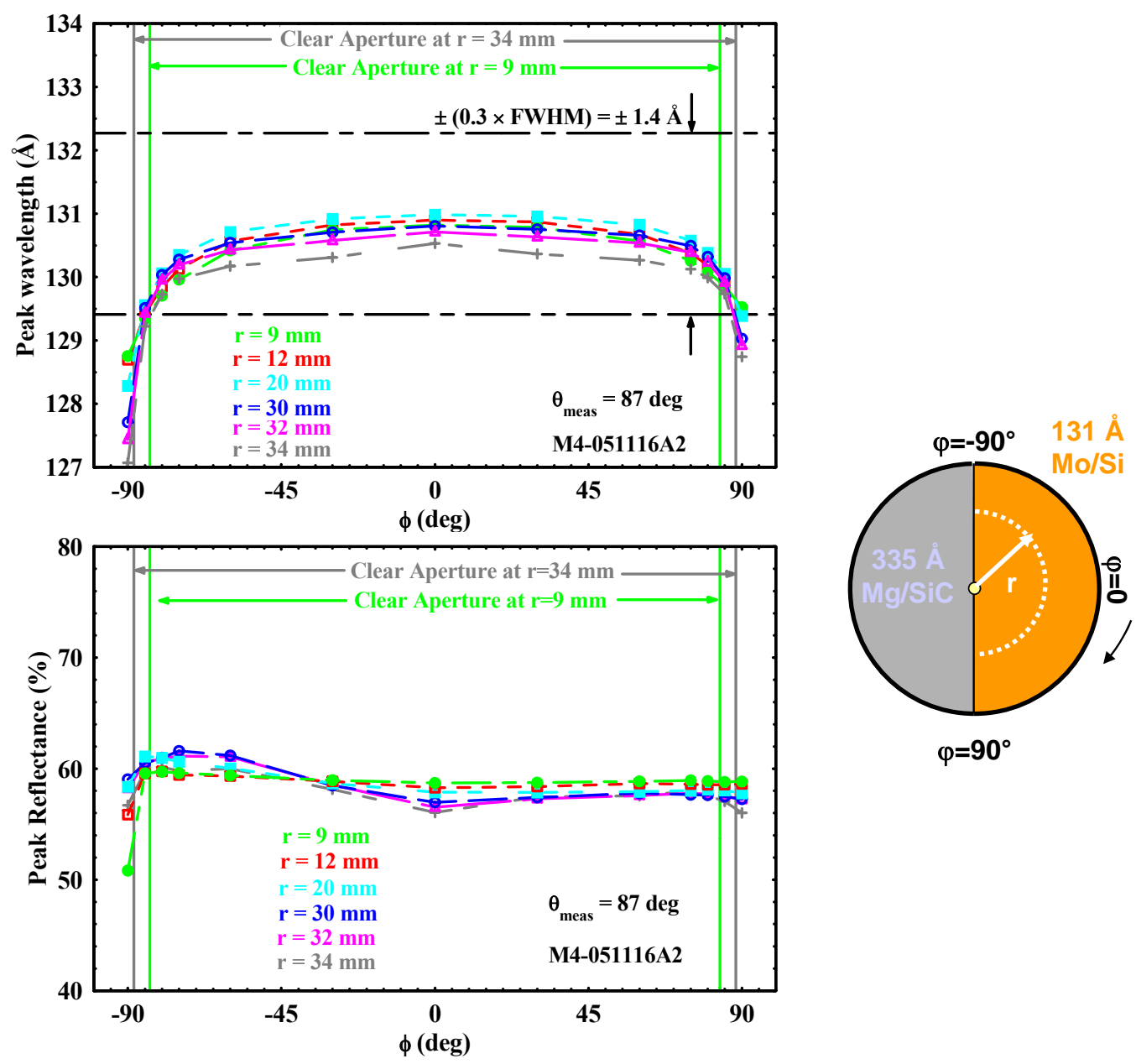

Figure 9: Peak wavelength (top) and reflectance (bottom) results for the secondary mirror, measured at 78 locations across the surface.

As is shown in Figs. 8, 9, for $\varphi$ approaching $\pm 90^{\circ}$ (near the edge of the D-shaped mask) or for $\mathrm{r}$ approaching the edge of the optic (near the edge of the coating fixtures) the wavelength uniformity is limited by shadowing effects. We have minimized shadowing effects by modifying fixtures and masks during the development phase of this project, to optimize wavelength uniformity ${ }^{14}$. 
The results of EUV reflectance measurements vs. radius on the two witness Si wafers are plotted in Fig. 10. In the region within $y= \pm 25 \mathrm{~mm}$ where the AIA coating witness pieces were cut from wafer $\mathrm{A} 1$, wavelength uniformity is within $\pm 0.02 \% \mathrm{P}-\mathrm{V}$ and reflectance is $68.3 \pm 0.1 \%$.

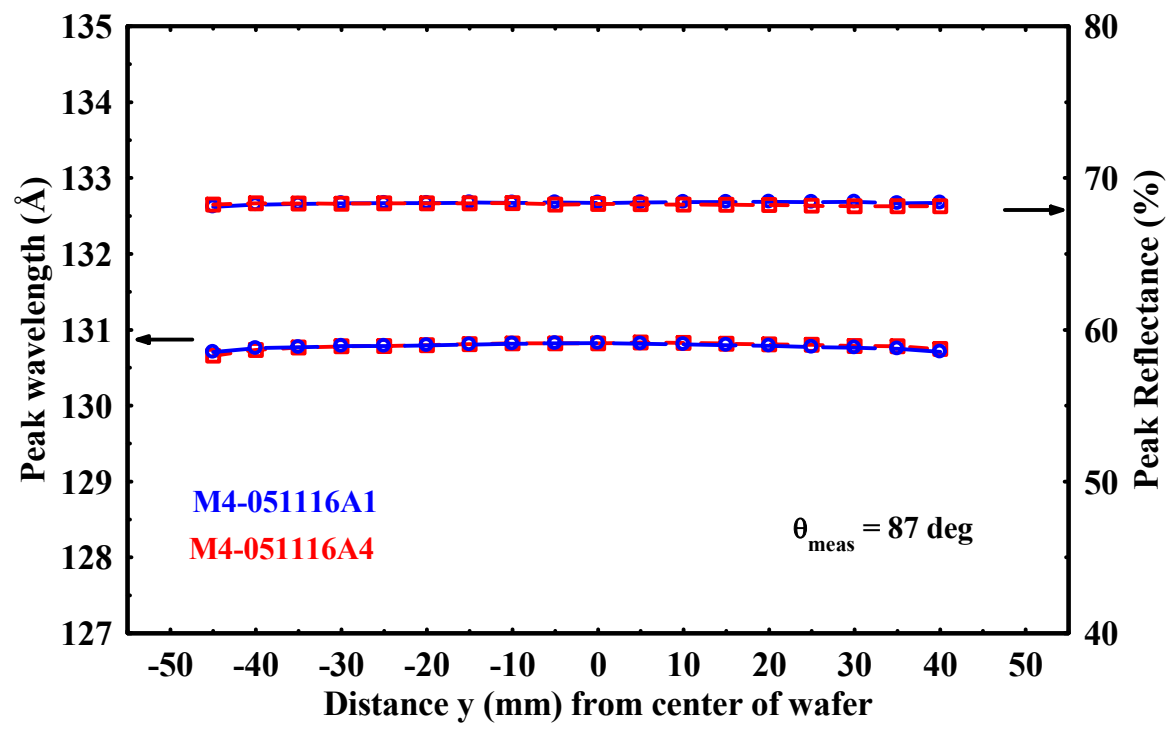

Figure 10: EUV reflectance measurements vs. radius on two witness Si wafers multilayer-coated during the flight deposition run.

\section{REFERENCES}

\footnotetext{
${ }^{1}$ R. Soufli, E. Spiller, M. A. Schmidt, J. C. Davidson, R. F. Grabner, E. M. Gullikson, B. B. Kaufmann, S. L. Baker, H. N. Chapman, R. M. Hudyma, J. S. Taylor, C. C. Walton, C. Montcalm, and J. A. Folta, "Multilayer optics for an extreme ultraviolet lithography tool with $70 \mathrm{~nm}$ resolution," in Emerging Lithographic Technologies V, E. A. Dobisz ed., Proc. SPIE 4343, 51-59 (2001).

${ }^{2}$ R. Soufli,, J.C. Robinson, E. Spiller, A. Aquila, E. M. Gullikson, "Update on multilayer thickness optimization using spherical AIA test substrates", report to SAO, December 17, 2004.

${ }^{3}$ R. Soufli et al, "LLNL_Phase A_report.doc", report to SAO, September 2004.

${ }^{4}$ R. Soufli, D. L. Windt, J. C. Robinson, E. A. Spiller, F. J. Dollar, A. L. Aquila, E. M. Gullikson, B. Kjornrattanawanich, J. F. Seely, L. Golub "Development and testing of EUV multilayer coatings for the atmospheric imaging assembly instrument aboard the Solar Dynamics Observatory", Proc. SPIE 5901, 59010M (2005).

${ }^{5}$ J. H. Underwood, E. M. Gullikson, "High-resolution, high-flux, user friendly VLS beamline at the ALS for the 50-1300 eV energy region," J.Electr. Spectr. Rel. Phenom. 92, 265-272 (1998).

${ }^{6}$ E. M. Gullikson, S. Mrowka, B. B. Kaufmann, "Recent developments in EUV reflectometry at the Advanced Light Source," in Emerging Lithographic Technologies V, E. A. Dobisz eds., Proc. SPIE 4343, 363-373 (2001).

${ }^{7}$ B. L. Henke, E. M. Gullikson, and J. C. Davis, "X-ray interactions: photoabsorption, scattering, transmission, and reflection at E= 50-30,000 eV, Z=1-92," At. Data Nucl. Data Tables 54, 181-342 (1993); an updated version of these data is available at http://www-cxro.lbl.gov.
} 
${ }^{8}$ R. Soufli and E. M. Gullikson, "Absolute photoabsorption measurements of molybdenum in the range 60 to $930 \mathrm{eV}$ for optical constant determination," Appl. Opt. 37, 1713-1719 (1998).

${ }^{9}$ R. Soufli and E. M. Gullikson, "Reflectance measurements on clean surfaces for the determination of optical constants of silicon in the extreme ultraviolet-soft-x-ray region," Appl. Opt. 36, 5499-5507 (1997).

${ }^{10}$ R. Soufli, S. L. Baker and J.C. Robinson, "Atomic Force Microscope (AFM) measurements and analysis on Sagem 04R0416 primary substrate", report to SAO, August 22, 2005.

${ }^{11}$ R. Soufli, S. L. Baker and J.C. Robinson, "Atomic Force Microscope (AFM) measurements and analysis on Sagem 04R0420 secondary substrate", report to SAO, October 25, 2005.

${ }^{12}$ V. Holy and T. Baumbach, "Non-specular x-ray reflection from rough multilayers," Phys. Rev. B 49,10668-76 (1994).

${ }^{13}$ D. G. Stearns, "Stochastic model for thin film growth and erosion," Appl. Phys. Lett. 62, 1745-7 (1993).

${ }^{14}$ R. Soufli, J. C. Robinson, J. Ayers, E. Spiller, A. L. Aquila, F. J. Dollar, E. M. Gullikson, "Update on multilayer profile optimization using spherical AIA test substrates after D-mask modifications", report to SAO, April 2, 2005. 